\title{
DÜBLIN
}

Technological University Dublin

ARROW@TU Dublin

\section{PI and PID controller tuning rules: an overview and personal perspective}

\author{
Aidan O'Dwyer \\ Technological University Dublin, aidan.odwyer@tudublin.ie
}

Follow this and additional works at: https://arrow.tudublin.ie/engscheleart

Part of the Controls and Control Theory Commons

\section{Recommended Citation}

O'Dwyer, Aidan : PI and PID controller tuning rules: an overview and personal perspective. Proceedings of the IET Irish Signals and Systems Conference, pp. 161-166, Dublin Institute of Technology, June, 2006. doi:10.21427/ekry-ap03

This Conference Paper is brought to you for free and open access by the School of Electrical and Electronic Engineering at ARROW@TU Dublin. It has been accepted for inclusion in Conference papers by an authorized administrator of ARROW@TU Dublin. For more information, please contact arrow.admin@tudublin.ie, aisling.coyne@tudublin.ie,gerard.connolly@tudublin.ie.

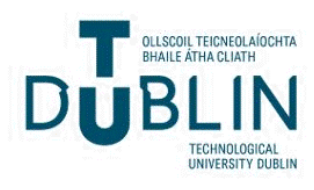




\title{
PI and PID controller tuning rules: an overview and personal perspective
}

\author{
Aidan O'Dwyer \\ School of Control Systems and Electrical Engineering, \\ Dublin Institute of Technology, \\ Kevin St., Dublin 8, Ireland \\ E-mail: aidan.odwyer@dit.ie
}

\begin{abstract}
The ability of PI and PID controllers to compensate many practical processes has led to their wide acceptance in industrial applications. The requirement to choose two or three controller parameters is most easily done using tuning rules. Starting with a general discussion of industrial practice, the paper provides a survey of additional tuning rules for continuous-time PI and PID control of time-delayed single-input, single-output (SISO) processes, to those explored in a recent book by the author.
\end{abstract}

\section{INTRODUCTION}

A time delay may be defined as the time interval between the start of an event at one point in a system and its resulting action at another point in the system. Delays are also known as transport lags or dead times; they arise in physical, chemical, biological and economic systems, as well as in the process of measurement and computation. Methods for the compensation of time delayed processes may be broadly divided into parameter optimised controllers, such as proportional-integral (PI) or proportional-integral-derivative (PID) controllers, in which the controller parameters are adapted to the controller structure, and structurally optimised controllers, in which the controller structure and parameters are adapted optimally to the structure and parameters of the process model.

PI and PID controllers have been at the heart of control engineering practice for seven decades. Historically, the first tuning rule (formula) for setting up controller parameters was defined in 1934 for the design of a proportional-derivative (PD) controller for a process exactly modelled by an integrator plus delay (IPD) model [1]. Subsequently, tuning rules were defined for PI and PID controllers, assuming the process was exactly modelled by a first order lag plus delay (FOLPD) model [2] or a pure delay model [2], [3].

The use of the PI or PID controller is ubiquitous in industry. It has been stated, for example, that in process control applications, more than $95 \%$ of the controllers are of PI or PID type [4-9]. Neglected by the academic research community until recently, work by K.J. Åström, T. Hägglund and F.G. Shinskey, among others, has sparked a revival of interest in the use of this "workhorse" of controller implementation. One illustrative statistic is worth quoting: the author has discovered that 293 of the
408 separate sources of tuning rules have been recorded since 1992.

However, despite this development work, surveys indicating the state of the art of control industrial practice report sobering results. For example, in testing of thousands of control loops in hundreds of plants, it has been found that more than $30 \%$ of installed PI/PID controllers are operating in manual mode and $65 \%$ of loops operating in automatic mode produce less variance in manual than in automatic (thus, the automatic controllers are poorly tuned) [10]. Another interesting such comment comes from [11], in which it is stated that PI/PID controllers are sometimes deliberately detuned by operating staff for steady state operation. A typical control system audit is quoted, comprising 300 loops, in which 46 controllers were operated with default tuning parameters in the controller. Other such literature [12] claims that "extensive industry testing" shows that $75 \%$ of all PID based loops are out of tune. A survey of paper processing mills is quoted, in which $60 \%$ of the 36 mills surveyed stated that less than half of their control loops were well tuned (the majority of the mills reported that they had between 2000 and 4000 regulatory control loops). In a further such comment, it is claimed [13] that only $20 \%$ of all control loops surveyed in mill audits have been found to actually reduce process variability in automatic mode over the short term. Of the problem loops, increased process variability in automatic mode could be ascribed specifically to controller tuning problems in approximately $30 \%$ of cases. Many of the points made above are re-iterated by [14]. The situation has not improved more recently, with [15] reporting that $80 \%$ of PID controllers are badly tuned; $30 \%$ of PID controllers operate in manual with another $30 \%$ of the controlled loops increasing the short-term variability of the process to be controlled (typically 
due to too strong integral action). It is stated that $25 \%$ of all PID controller loops use default factory settings, implying that they have not been tuned at all.

Thus, there is strong evidence that PI and PID controllers remain poorly understood and, in particular, poorly tuned in many applications. Process performance deteriorates when the controller is poorly tuned; this deterioration may be reflected, for example, in a reduction in energy efficiency and increased environmental emissions. The net effect will be an increase in operating costs and a reduction in overall competitiveness. However, good controller tuning, for example, can allow the recovery of up to $6 \%$ of energy costs, in a variety of industries [16]. Poor controller tuning is surprising, as very many tuning rules exist to allow the specification of the controller parameters. Tuning rules have the advantage of ease of calculation of the controller parameters (when compared to more analytical controller design methods), on the one hand; on the other hand, the use of tuning rules is a good alternative to trial and error tuning. It is clear that the many controller tuning rules proposed in the literature are not having an impact on industrial practice. One reason is that the tuning rules are not very accessible, being scattered throughout the control literature; in addition, the notation used is not unified. In a book published in 2003 [17], PI and PID controller tuning rules for processes with time delay have been brought together and summarised, using a unified notation. A second edition of this book is due to be published in 2006 [18].

This paper provides a survey of additional tuning rules for continuous-time PI and PID control of single-input, single-output (SISO) processes, with time delay, to those explored in [17]. Firstly, a brief summary of the range of PI and PID controller structures proposed in the literature, together with the process models used to define the controller tuning rules, is provided. Then, controller architecture and process modeling issues are outlined. Subsequently, space considerations dictate that just an outline of additional tuning rules for setting up PI and PID controllers, for a number of process models, may be provided; further details of the tuning rules will be provided at the conference. Finally, conclusions to the paper are drawn. Other reviews are recommended to the interested reader [19]-[35].

\section{CONTROLLER ARCHITECTURE AND PROCESS MODELLING}

A practical difficulty with PID control technology is a lack of industrial standards, which has resulted in a wide variety of PID controller architectures. Seven different structures for the PI controller and forty-six different structures for the PID controller have been identified. Controller manufacturers vary in their choice of architecture; controller tuning that works well on one architecture may work poorly on another. Details are given in [17], [18]; considering the PID controller, common architectures are:

1. The 'ideal' PID controller (Figure 1), given by

$$
\mathrm{G}_{\mathrm{c}}(\mathrm{s})=\mathrm{K}_{\mathrm{c}}\left(1+\frac{1}{\mathrm{~T}_{\mathrm{i}} \mathrm{s}}+\mathrm{T}_{\mathrm{d}} \mathrm{s}\right)
$$

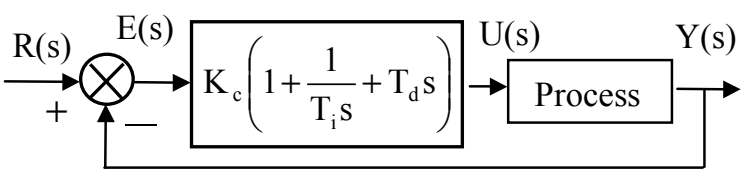

Figure 1. Ideal PID controller in a unity feedback block diagram representation. This controller structure, and an equivalent structure, is also labelled the parallel, ideal parallel, non-interacting, parallel non-interacting, independent, gain independent or ISA controller [17], [18]. 276 tuning rules have been identified for this controller structure.

This architecture is used, for example, on the Honeywell TDC3000 Process Manager Type A, non-interactive mode product [36].

2. The 'classical' PID controller (Figure 2), given by

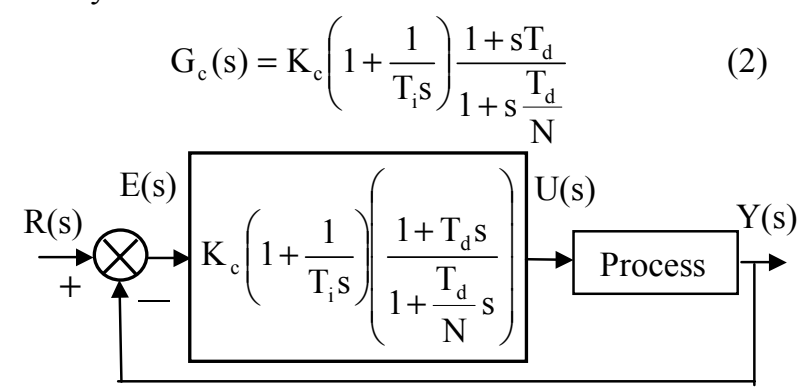

Figure 2. Classical PID controller in a unity feedback block diagram representation. Also labelled the cascade, interacting, series, interactive, rate-before-reset or analog controller [17], [18], 101 tuning rules have been identified for this controller structure.

This architecture is used, for example, on the Honeywell TDC3000 Process Manager Type A, interactive mode product [36].

3. The non-interacting controller based on the two degree of freedom structure (Figure 3), given by

$$
\begin{aligned}
U(s)=K_{c}\left(1+\frac{1}{T_{i} s}+\right. & \left.\frac{T_{d} s}{1+\frac{T_{d}}{N} s}\right) E(s) \\
& -K_{c}\left(\alpha+\frac{\beta T_{d} s}{1+\frac{T_{d}}{N} s}\right) R(s)
\end{aligned}
$$




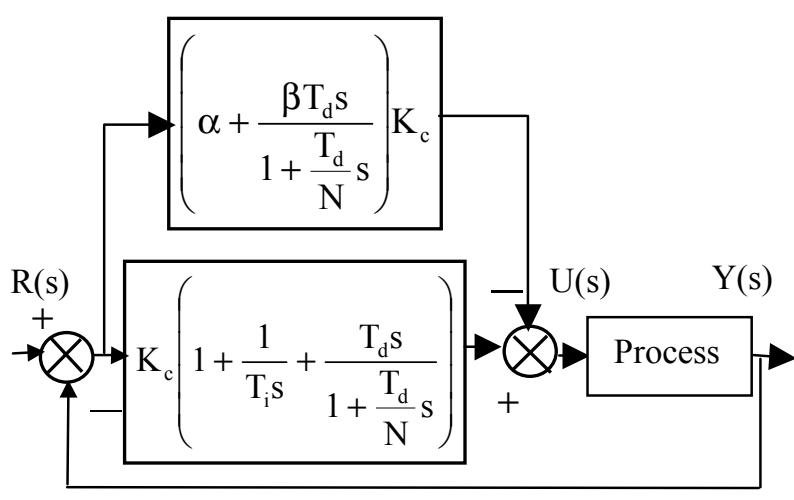

Figure 3. Non-interacting controller, based on the two degree of freedom structure, in a unity feedback block diagram representation. Also labelled the m-PID or ISA-PID controller [17], [18], 44 tuning rules have been identified for this controller structure.

This architecture is used, for example, on the Omron E5CK digital controller with $\beta=1$ and $\mathrm{N}$ $=3[36]$.

The most dominant PI controller architecture is the 'ideal' PI controller, given by

$$
\mathrm{G}_{\mathrm{c}}(\mathrm{s})=\mathrm{K}_{\mathrm{c}}\left(1+\frac{1}{\mathrm{~T}_{\mathrm{i}} \mathrm{s}}\right)
$$

The wide variety of controller architectures is mirrored by the wide variety of ways in which processes with time delay may be modeled. Common models are:

1. Stable FOLPD model, given by

$$
\mathrm{G}_{\mathrm{m}}(\mathrm{s})=\frac{\mathrm{K}_{\mathrm{m}} \mathrm{e}^{-\mathrm{s \tau} \tau_{\mathrm{m}}}}{1+\mathrm{s} \mathrm{T}_{\mathrm{m}}}
$$

2. IPD model, given by

$$
\mathrm{G}_{\mathrm{m}}(\mathrm{s})=\frac{\mathrm{K}_{\mathrm{m}} \mathrm{e}^{-\mathrm{s \tau} \tau_{\mathrm{m}}}}{\mathrm{s}}
$$

3. First order lag plus integral plus delay (FOLIPD) model, given by

$$
\mathrm{G}_{\mathrm{m}}(\mathrm{s})=\frac{\mathrm{K}_{\mathrm{m}} \mathrm{e}^{-\mathrm{s \tau} \tau_{\mathrm{m}}}}{\mathrm{s}\left(1+\mathrm{sT}_{\mathrm{m}}\right)}
$$

4. Second order system plus time delay (SOSPD) model, given by

$$
\begin{aligned}
& \mathrm{G}_{\mathrm{m}}(\mathrm{s})=\frac{\mathrm{K}_{\mathrm{m}} \mathrm{e}^{-\mathrm{s \tau} \tau_{\mathrm{m}}}}{\mathrm{T}_{\mathrm{m} 1} \mathrm{~s}^{2}+2 \xi_{\mathrm{m}} \mathrm{T}_{\mathrm{m} 1} \mathrm{~s}+1} \\
& \text { or } \mathrm{G}_{\mathrm{m}}(\mathrm{s})=\frac{\mathrm{K}_{\mathrm{m}} \mathrm{e}^{-\mathrm{s} \tau_{\mathrm{m}}}}{\left(1+\mathrm{T}_{\mathrm{m} 1} \mathrm{~s}\right)\left(1+\mathrm{T}_{\mathrm{m} 2} \mathrm{~s}\right)}
\end{aligned}
$$

Some $82 \%$ of the PI controller tuning rules identified have been defined for the ideal PI controller structure, with $42 \%$ of tuning rules based on a FOLPD process model. The range of PID controller variations has led to a less homogenous situation than for the PI controller; $40 \%$ of tuning rules identified have been defined for the ideal PID controller structure, with $37 \%$ of PID tuning rules based on a FOLPD process model [18].
Of course, the modeling strategy used influences the value of the model parameters, which, in turn, affect the controller values determined from the tuning rules. Forty-one modeling strategies have been detailed to determine the parameters of the FOLPD process model, for example. Space does not permit a full discussion of this issue; further details are provided in [17], [18].

\section{ADDITIONAL TUNING RULES FOR PI AND PID CONTROLLERS}

Before considering additional tuning rules for PI and PID controllers over those proposed in [17], it is timely to review the action of the PID controller. Considering the ideal PID controller, for example, which is given by

$$
\mathrm{G}_{\mathrm{c}}(\mathrm{s})=\mathrm{K}_{\mathrm{c}}\left(1+\frac{1}{\mathrm{~T}_{\mathrm{i}} \mathrm{s}}+\mathrm{T}_{\mathrm{d}} \mathrm{s}\right)
$$

with $\mathrm{K}_{\mathrm{c}}=$ proportional gain, $\mathrm{T}_{\mathrm{i}}=$ integral time constant and $\mathrm{T}_{\mathrm{d}}=$ derivative time constant. If $\mathrm{T}_{\mathrm{i}}=\infty$ and $\mathrm{T}_{\mathrm{d}}=0$ (that is, $\mathrm{P}$ control), then the closed loop measured value is always less than the desired value for processes without an integrator term, as a positive error is necessary to keep the measured value constant, and less than the desired value. The introduction of integral action facilitates the achievement of equality between the measured value and the desired value, as a constant error produces an increasing controller output. The introduction of derivative action means that changes in the desired value may be anticipated, and thus an appropriate correction may be added prior to the actual change. Thus, in simplified terms, the PID controller allows contributions from present, past and future controller inputs.

PI and PID controller tuning rules may be broadly classified as follows:

- Tuning rules based on a measured step response

- Tuning rules based on minimising an appropriate performance criterion

- $\quad$ Tuning rules that give a specified closed loop response

- Robust tuning rules, with an explicit robust stability and robust performance criterion built in to the design process

- $\quad$ Tuning rules based on recording appropriate parameters at the ultimate frequency.

Tuning rules in the first four subdivisions are typically based on process model parameters; the development of a process model is typically not required for using tuning rules in the final subdivision above. Some tuning rules could be considered to belong to more than one subdivision, so the subdivisions cannot be considered to be mutually exclusive; nevertheless, they provide a convenient way to classify the rules. An outline of tuning rules in these subdivisions is now provided; 
these tuning rules are, with the exception of [37], additional to those considered in [17].

Tuning rules based on a measured step response are also called process reaction curve methods. The first (and most well-known) tuning rule of this type was suggested in 1942 [37]; in this method, the process is modeled by a FOLPD process model with the model parameters estimated using a tangent and point method, as indicated in Figure 4. Simple formulae are used to define tuning parameters for PI and PID controllers. The PI controller settings are given by

$$
\mathrm{K}_{\mathrm{c}}=\frac{0.9 \mathrm{~T}_{\mathrm{m}}}{\mathrm{K}_{\mathrm{m}} \tau_{\mathrm{m}}}, \mathrm{T}_{\mathrm{i}}=3.33 \tau_{\mathrm{m}}
$$

The (ideal) PID controller settings are given by

$$
\mathrm{K}_{\mathrm{c}} \in\left[\frac{1.2 \mathrm{~T}_{\mathrm{m}}}{\mathrm{K}_{\mathrm{m}} \tau_{\mathrm{m}}}, \frac{2 \mathrm{~T}_{\mathrm{m}}}{\mathrm{K}_{\mathrm{m}} \tau_{\mathrm{m}}}\right], \mathrm{T}_{\mathrm{i}}=2 \tau_{\mathrm{m}}, \mathrm{T}_{\mathrm{d}}=0.5 \tau_{\mathrm{m}}
$$

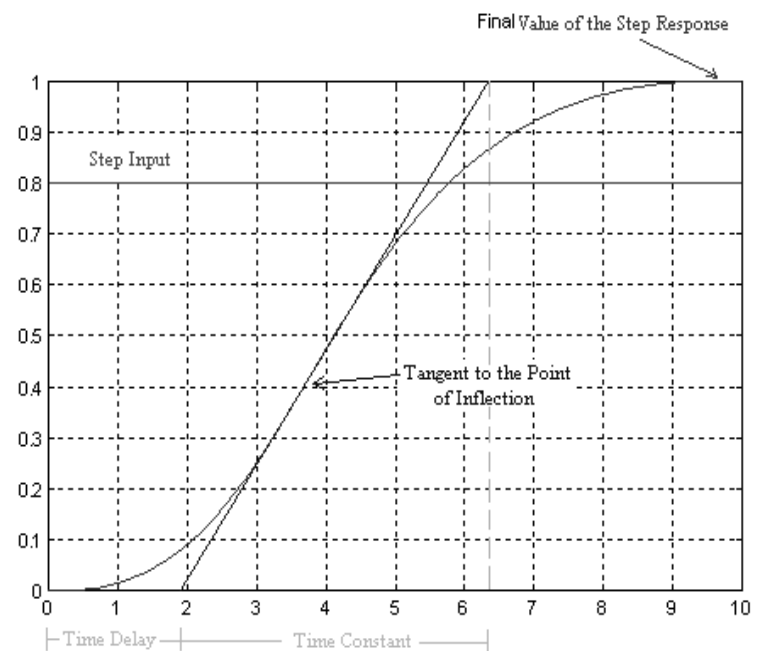

Figure 4. Tangent and point method [37] for developing a process model. $\mathrm{K}_{\mathrm{m}}=$ model gain $=$ ratio of the steady state change in process output to steady state change in process input, $\mathrm{T}_{\mathrm{m}}=$ model time constant and $\tau_{\mathrm{m}}=$ model time delay. 54 controller tuning rules have been identified based on the model parameters determined from this modelling method. 21 of the 47 other modelling methods for determining such a process model, prior to specifying tuning rules, are based on data gathered from the open loop process step or impulse response [18].

Other process reaction curve tuning rules are also described, sometimes in graphical form, to control processes modeled by a variety of time-delayed models [18]. The advantage of process reaction curve tuning strategies is that only a single experimental test is necessary. However, the disadvantages of the strategy are primarily based on the difficulty, in practice, of obtaining an accurate process model; for example, load changes may occur during the test which may distort the test results and a large step input may be necessary to achieve a good signal to noise ratio [38]. Similar disadvantages will arise in any tuning method dependent on prior model development.

Tuning rules based on minimising an appropriate performance criterion may be defined either for optimum regulator or optimum servo action. Performance criteria, such as the minimisation of the integral of absolute error (IAE) in a closed loop environment, may be used to determine a unique set of controller parameter values. Tuning rules have been described, sometimes in graphical form, to optimise the regulator response, servo response or other characteristics of a compensated delayed process, represented by a variety of models [18].

Tuning rules that give a specified closed loop response (direct synthesis tuning rules) may be defined by specifying a time domain related metric, such as the desired poles of the closed loop response. The definition may be expanded to cover techniques that allow the achievement of a frequency domain metric, such as a specified gain margin and/or phase margin. Tuning rules of this type have been specified to compensate a delayed process, represented by a variety of models [18].

Robust tuning rules have an explicit robust stability and/or robust performance criterion built in to the design process. Tuning rules of this type have also been specified to compensate a delayed process, represented by a variety of models [18].

Ultimate cycle tuning rules are based on recording appropriate parameters at the ultimate frequency (that is, the frequency at which marginal stability of the closed loop control system occurs). The first such tuning rule was defined in 1942 [37] for the tuning of P, PI and PID controller parameters of a process that may or may not include a delay. Briefly, the experimental technique is as follows:

a) Place the controller in proportional mode only

b) Increase $K_{c}$ until the closed loop system output goes marginally stable; record $\mathrm{K}_{\mathrm{c}}$ (calling it $\mathrm{K}_{\mathrm{u}}$, the ultimate gain), and the ultimate period, $\mathrm{T}_{\mathrm{u}}$. A typical marginally stable output, recorded on a laboratory flow process, is shown in Figure 5.

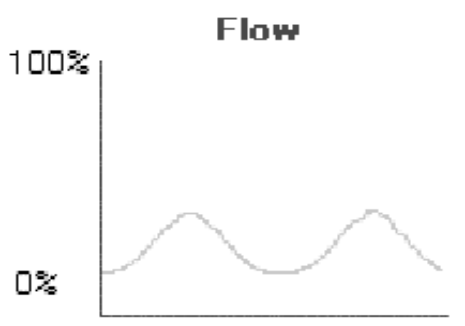

Figure 5. Typical marginally stable process variable pattern. Note that the pattern exhibits evidence of a process nonlinearity, which is common in real applications. Over 129 controller tuning rules have been defined, based on the data determined from such a pattern [18].

Simple formulae are used to define tuning parameters for PI and PID controllers. The PI controller settings are given by

$$
\mathrm{K}_{\mathrm{c}}=0.45 \mathrm{~K}_{\mathrm{u}}, \mathrm{T}_{\mathrm{i}}=0.83 \mathrm{~T}_{\mathrm{u}}
$$

with the (ideal) PID controller settings given by 


$$
\mathrm{K}_{\mathrm{c}}=0.6 \mathrm{~K}_{\mathrm{u}}, \mathrm{T}_{\mathrm{i}}=0.5 \mathrm{~T}_{\mathrm{u}}, \mathrm{T}_{\mathrm{d}}=0.125 \mathrm{~T}_{\mathrm{u}}
$$

The tuning rules implicitly build an adequate frequency domain stability margin into the compensated system [39]. However, there are a number of disadvantages to the ultimate cycle tuning approach:

- the system must generally be destabilised under proportional control

- the empirical nature of the method means that uniform performance is not achieved in general [40]

- several trials must typically be made to determine the ultimate gain

- the resulting process upsets may be detrimental to product quality

- there is a danger of misinterpreting a limit cycle as representing the stability limit [41] and

- the amplitude of the process variable signal may be so great that the experiment may not be carried out for cost or safety considerations.

Some of these disadvantages are addressed by defining modifications of the rules in which, for example, the proportional gain in the experiment is set up to give a closed loop transient response decay ratio of 0.25 , or a phase lag of $135^{\circ}$. Ultimate cycle tuning rules, and their modifications, have been specified to compensate general, possibly delayed processes, represented by a variety of models [18].

\section{CONCLUSIONS}

Control academics and practitioners remain interested in the use of PI and PID controllers. PID controller tuning rules can be directly implemented in a number of applications. The outcome is directly measurable in, for example, energy savings and waste reduction (including greenhouse gas emission reduction). This paper summarises mainly recent work in tuning rule development for processes with time delays, updating the information provided in [17]. The most startling statistic to emerge from the complete work is the quantity of tuning rules identified to date; 443 PI tuning rules and 691 PID tuning rules, a total of 1134 separate rules. Recent years have seen an acceleration in the accumulation of tuning rules. In general, there is a lack of comparative analysis regarding the performance and robustness of closed loop systems compensated with controllers whose parameters are chosen using the tuning rules; associated with this is the lack of benchmark processes, at least until relatively recently [42]. The main priority for future research in the area should be a critical analysis of available tuning rules, rather than the proposal of further tuning rules.

Historical note: The $70^{\text {th }}$ anniversary of the receipt of the first technical paper describing tuning rules for setting up controller parameters [2] is presently being marked. The paper was received by the Philosophical
Transactions of the Royal Society of London on July 15, 1935; the paper was received, in revised form, on November 26, 1935 and was read on February 2, 1936. The lead author of the paper subsequently took out a patent on the PID controller (Callender, A. and Stevenson, A.B., Automatic control of variable physical characteristics, US patent 2,175,985. Filed: Feb. 17, 1936; Issued Oct. 10, 1939).

\section{REFERENCES}

[1] A. Callendar, Preliminary notes on automatic control, I.C.I. Alkali Ltd., Northwich, U.K., Central File No. R.525/15/3, 1934.

[2] A. Callendar, D.R. Hartree, and A. Porter, "Time-lag in a control system", Phil. Trans. Royal Society of London Series A, vol. 235, pp. 415-444, 1935/6.

[3] D.R. Hartree, A. Porter, A. Callender and A.B. Stevenson, "Time-lag in a control system - II", Proc. Royal Society of London, vol. 161(A), pp. 460-476, 1937.

[4] K.J. Åström and T. Hägglund, PID Controllers: Theory, Design and Tuning. Research Triangle Park, NC: Instrument Society of America, 1995.

[5] H.N. Koivo and J.T. Tanttu, "Tuning of PID Controllers: Survey of SISO and MIMO techniques" in Proc. IFAC Intelligent Tuning Adaptive Control Symp., Singapore, pp. 75-80, 1991.

[6] W.L. Bialkowski, in The Control Handbook, W.S. Levine, Ed. Boca Raton, Florida: CRC/IEEE Press, pp. 1219-1242, 1996.

[7] W.L. Luyben and M.L. Luyben, Essentials of process control. Singapore: McGraw-Hill International Edition, 1997.

[8] M.A. Hersh and M.A. Johnson, "A study of advanced control systems in the workplace", Control Eng. Practice, vol. 5, no. 6, pp. 771-778, 1997.

[9] H. Takatsu and T. Itoh, "Future needs for control theory in industry - report of the control technology survey of Japanese industry", IEEE Trans. Control Syst. Tech., vol. 7, no. 3, pp. 298-305, 1999.

[10] D.B. Ender, "Process control performance: not at good as you think", Control Eng., pp. 180-190, September 1993.

[11] Protuner U.K. Ltd, The state of art in control, Sales literature, 1997.

[12] Universal Dynamic Technologies, Brainwave: the new concept in process control, Sales literature, 1998.

[13] Entech Control Engineering Ltd., Competency in Process Control - Industry Guidelines. Version 1.0, 3/94, 1994

[14] C.-C. Yu, Autotuning of PID controllers. London, U.K.: Advances in Industrial Control Series, Springer-Verlag, 1999.

[15] P. Van Overschee and B. De Moor, "RaPID: the end of heuristic PID tuning", in Preprints Proc. PID '00: IFAC Workshop, Terrassa, Spain, pp. 687-692, 2000.

[16] Case histories accompanying Good Practice Guide 346 (Improving the effectiveness of basic closed loop control systems), The Carbon Trust. Available at www.thecarbontrust.co.uk (accessed December 2005).

[17] A. O'Dwyer, Handbook of PI and PID controller tuning rules. London, U.K.: Imperial College Press, $1^{\text {st }}$ edition, 2003. 
[18] A. O'Dwyer, Handbook of PI and PID controller tuning rules. London, U.K.: Imperial College Press, $2^{\text {nd }}$ edition, 2006.

[19] D.E. Seborg, T.F. Edgar and S.L. Shah, "Adaptive control strategies for process control: a survey", AIChE J., vol. 32, pp. 881-913, 1986.

[20] S.S. Bueno, R.M.C. De Keyser and G. Favier, "Autotuning and adaptive tuning of PID controllers", Journal A, vol. 32, no. 1, pp. 28-34, 1991.

[21] D.G. Fisher, "Process control: an overview and personal perspective", Canadian J. Chem. Eng., vol. 69, pp. 5-26, 1991.

[22] K.J. Åström, T. Hägglund, C.C. Hang and W.K. Ho, "Automatic tuning and adaptation for PID controllers - a survey”, Control Eng. Practice, vol. 1, pp. 699714, 1993.

[23] K.J. Åström, T.H. Lee, K.K. Tan and K.H. Johansson, "Recent advances in relay feedback methods - a survey", in Proc. IEEE Int. Conf. Systems, Man Cybernetics, Vancouver, British Columbia, pp. 2616-2621, 1995.

[24] K.J. Åström, "Tuning and adaptation", in Proc. $13^{\text {th }}$ IFAC World Congress, San Francisco, U.S.A., Plenary Volume, pp. 1-18, 1996.

[25] G. Chen, "Conventional and fuzzy PID controllers: an overview", Int. J. Intelligent Control and Systems, vol. 1, no. 2, pp. 235-246, 1996.

[26] M.A. Unar, D.J. Murray-Smith and S.F.A. Shah, Technical Report CSC-96016, 1996. Available at http://www.mech.gla.ac.uk/Research/Control/Publica tions/Rabstracts/abs96016.html (accessed December 2005).

[27] R. Gorez, "A survey of PID auto-tuning methods", Journal A, vol. 38, pp. 3-10, 1997.

[28] K.K. Tan, Q.G. Wang, C.C. Hang and T.J. Hägglund. Advances in PID control, London, U.K.: Advances in Industrial Control Series, SpringerVerlag, 1999.

[29] K.J. Åström and T. Hägglund, "The future of PID control" in Preprints Proc. PID '00: IFAC Workshop, Terrassa, Spain, pp. 19-30, 2000.

[30] M. Lelic and Z. Gajic, "A reference guide to PID controllers in the nineties" in Preprints Proc. PID '00: IFAC Workshop, Terrassa, Spain, pp. 73-82, 2000.

[31] P. Cominos and N. Munro, "PID controllers: recent tuning methods and design to specification", IEE Proc. - Control Theory Applic., vol. 149, no. 1, pp. 46-53, 2002.

[32] C.C. Hang, K.J. Åström and Q.G. Wang, "Relay feedback auto-tuning of process controllers - a tutorial review", J. Process Control, vol. 12, pp. 143162, 2002.

[33] A. O'Dwyer, "PID compensation of time delayed processes: a survey", in Proc. Irish Signals Systems Conf., Dublin, Ireland, June 29-30, pp. 5-12, 2000.

[34] A. O'Dwyer, "PID compensation of time delayed processes 1998-2002: a survey", in Proc. American Control Conf., Denver, Colorado, USA, pp. 14941499, 2003.

[35] C.-H. Lee, "A survey of PID controller design based on gain and phase margins", International Journal of Computational Cognition, vol. 2, no. 3, pp. 63-100, 2004.

[36] ISMC. RAPID: Robust Advanced PID Control Manual. Intelligent System Modeling and Control nv, Belgium, 1999.
[37] J.G. Ziegler and N.B. Nichols, "Optimum settings for automatic controllers", Trans. ASME, vol. 64, pp. 759-768, 1942.

[38] D.E. Seborg, T.F. Edgar and D.A. Mellichamp, Process dynamics and control, New York: John Wiley and Sons, 1989.

[39] A.M. De Paor, "A fiftieth anniversary celebration of the Ziegler-Nichols PID controller", Int. J. Elect. Eng. Education, vol. 30, pp. 303-316, 1993.

[40] S.-H. Hwang and T.-S. Tseng, "Process identification and control based on dominant pole expansions", Chem. Eng. Sci., vol. 49, no. 12, pp. 1973-1983, 1994.

[41] D.W. Pessen, "A new look at PID-controller tuning", Trans. ASME. J. Dyn. Sys., Meas. Control, vol. 116, no. 3, pp. 553-557, 1994.

[42] K.J. Åström and T. Hägglund, "Benchmark systems for PID control", in Preprints Proc. PID '00: IFAC Workshop, Terrassa, Spain, pp. 181-182, 2000. 